\title{
Chemically Induced Cryptic Sesquiterpenoids and Expression of Sesquiterpene Cyclases in Botrytis cinerea Revealed New Sporogenic (+)-4-Epieremophil-9-en-11-ols
}

\author{
Cristina Pinedo, ${ }^{\dagger, \perp}$ Javier Moraga, ${ }^{\dagger, \perp}$ Javier Barua, ${ }^{\dagger}$ Victoria E. González-Rodríguez, ${ }^{\ddagger}$ Josefina Aleu, ${ }^{\dagger}$
} Rosa Durán-Patrón, ${ }^{\dagger}$ Antonio J. Macías-Sánchez, ${ }^{\dagger}$ James R. Hanson, ${ }^{\S}$ Muriel Viaud, ${ }^{\|}$

Rosario Hernández-Galán, ${ }^{\dagger}$ Carlos Garrido, ${ }^{\ddagger}$ and Isidro G. Collado ${ }^{*}{ }^{\dagger}$

${ }^{\dagger}$ Departamento de Química Orgánica, Facultad de Ciencias, Universidad de Cádiz, Campus Universitario Río San Pedro s/n, Torre sur, $4^{\circ}$ planta, 11510, Puerto Real, Cádiz, Spain

${ }^{\ddagger}$ Departamento de Biomedicina y Biotecnología, Laboratorio de Microbiología, Facultad de Ciencias de Mar y Ambientales, Universidad de Cádiz, 11510, Puerto Real, Spain

${ }^{\S}$ Department of Chemistry, University of Sussex, Brighton, Sussex, BN1 9QJ, United Kingdom

"UMR BIOGER, INRA, Avenue Lucien Brétignières, 78850 Grignon, France

Supporting Information

ABSTRACT: The sequencing of the genomes of the B05.10 and T4 strains of the fungus Botrytis cinerea revealed an abundance of novel biosynthetic gene clusters, the majority of which were unexpected on the basis of the previous analyses of the fermentation of these and closely related species. By systematic alteration of easy accessible cultivation parameters, using chemical induction with copper sulfate, we have found a cryptic sesquiterpenoid family with new structures related to eremophil-9-ene, which had the basic structure of the sesquiterpene (+)-5-epiaristolochene ((+)-4-epieremophil-9ene). An expression study of the sesquiterpene cyclase genes
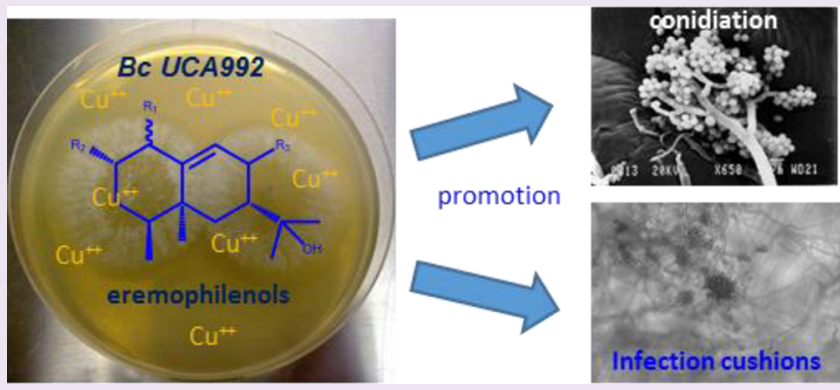
present in the Botrytis cinerea genome, under culture conditions, is reported. In general, a 3 day delay and a higher BcSTC genes expression were observed when copper $(5 \mathrm{ppm})$ was fed to the fermentation broth. In addition, to the observed effect on the $B c B O T 2$ ( BcSTC1) gene, involved in the biosynthesis of the botrydial toxin, a higher expression level for BcSTC3 and BcSTC4 was observed with respect to the control in the strain B05.10. Interestingly, under copper conditions, the BcSTC4 gene was the most expressed gene in the Botrytis cinerea UCA992 strain. In vitro evaluation of the biological role of these metabolites indicates that they contributed to the conidial development in B. cinerea and appear to be involved in self-regulation of the production of asexual spores. Furthermore, they promoted the formation of complex appressoria or infection cushions.

\begin{abstract}
A mong the many remarkable discoveries emerging from the genomics era is the revelation that most filamentous fungi possess a higher number of gene clusters encoding for the production of secondary metabolites than the number of natural products that have been isolated from the same organism. ${ }^{1-4}$ This indicates that the biosynthetic potential of these microorganisms has been barely explored, and as a result a significant number of cryptic metabolites remain undiscovered. $^{5}$

Botrytis cinerea Pers. is the causal agent of the economically important gray mold disease that affects more than 200 species of ornamental and agricultural plant hosts. As a necrotrophic and polyphagenous pathogen, the gray mold displays the capacity to kill host cells through the production of toxins, reactive oxygen species, and the induction of a plant-produced oxidative burst. ${ }^{6,7}$ Two groups of nonspecific phytotoxins have been identified (Figure 1), i.e., the sesquiterpene botrydial (1) and related compounds ${ }^{8}$ and 3 -acetylbotcinic acid (2) and its
\end{abstract}

botcinin (2a) derivatives. ${ }^{9,10}$ Botrydial (1) is produced during plant infection ${ }^{11}$ and induces chlorosis and cell collapse. ${ }^{8} 3$ Acetylbotcinic acid (2) and derivatives (2a) have also been shown to induce chlorosis and necrosis ${ }^{12}$ but also have antifungal activities. ${ }^{13}$ Furthermore, the sesquiterpenoid abscisic acid which mediates leaf fall (3) has been isolated from several strains of Botrytis. ${ }^{14}$

The recent availability of the $B$. cinerea genome at the Genoscope (http://www.genoscope.cns.fr/) provided the opportunity to investigate secondary metabolism gene clusters. The final manuscript with the Botrytis genome has been recently published. ${ }^{15}$ The sequencing of the genomes of the B05.10 and T4 strains of B. cinerea revealed an abundance of

\footnotetext{
Received: November 10, 2015

Accepted: February 22, 2016

Published: February 22, 2016
} 
<smiles>CC(=O)O[C@H]1C[C@@H](C)[C@@H](C=O)[C@@]2(O)[C@@H]1C(C)(C)CC2(C)C</smiles>

1 Botridial<smiles>CCOC1[C@@H](C)[C@@H](O)[C@@](C(=O)O)([C@H](C)[C@H](C)C(=O)O)O[C@@H]1C</smiles>

2 3-Acetylbotcinic acid<smiles>CC1=CC(=O)CC(C)(C)[C@]1(O)/C=C/C(C)=C\C(=O)O</smiles>

3 Abscisic acid

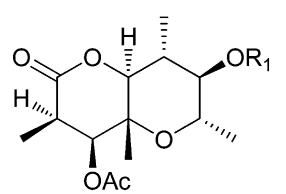

2a Botcinin A<smiles>[R]C(=O)/C=C/[C@H](O)CC</smiles>

Figure 1. Some metabolites isolated from B. cinerea.

novel biosynthetic gene clusters, the majority of which were unexpected on the basis of previous analyses of the fermentation of these and closely related species. These data revealed that $B$. cinerea has 43 key enzymes involved in the biosynthesis of secondary metabolites, including those putatively involved in the biosynthesis of sesqui- and diterpenes (STC, 6, and DTC, 3, respectively), polyketides (PKS, 22) and peptides (NRPS, 8). Some of these are specific to this phytopathogen. Therefore, $B$. cinerea has a high potential for the study of orphan biosynthetic genes and cryptic metabolites. $^{15}$

Copper is a toxic metal and also an essential trace element that serves as a cofactor for numerous enzymes. In fungi, copper-transporting ATPases are known to supply copper to various copper-containing proteins. Among proteins targeted by copper-transporting ATPases are the tyrosinases, laccases, and metallooxidase which are known to play important roles in melanization and pathogenicity. ${ }^{16}$

A copper-transporting ATPase gene $B c C c c 2$ has been identified in $B$. cinerea and in addition to pathogenicity, the melanization, conidiation, and the sclerotia formation were significantly affected in a $\Delta B c C c c 2$ null mutant. Interestingly, the impaired functions in $\Delta B c C c c 2$ mutants were restored when the cells were grown in a copper-supplemented medium. ${ }^{17}$

Our research group has observed, over the years, variations in the secondary metabolites profile of $B$. cinerea when certain changes have been made to the culture conditions. Based on those observations, we have undertaken an "OSMAC" (one strain many compounds) approach, ${ }^{18-20}$ by altering easily accessible cultivation parameters, such as media composition, aeration, temperature, or shape of culturing flask to induce the production of previously unknown compounds.

In this context, when the medium broth was supplemented with different sublethal amounts of copper, effects on the weight of the extract, morphological changes, especially melanization and conidiation, and differences in the metabolic profile were observed.

This paper deals with the study of the chemical induction of silent biosynthetic pathways and includes the study of the expression of the sesquiterpene cyclase genes present in the Botrytis genome and the isolation and structural characterization of a new family of cryptic sesquiterpenes that are produced by B. cinerea. Furthermore, the in vitro evaluation of the biological role of these metabolites indicates that they contribute to the conidial development in B. cinerea.

\section{RESULTS AND DISCUSSION}

As previously indicated, the $B$. cinerea genome has revealed that this phytopathogenic fungus has six putative sesquiterpene cyclase (BcSTC) genes clusters (BcSTC6, ID P020710.1, ${ }^{15}$ absent in the genome of the three studied strains). Sesquiterpenoids comprise a structurally diverse group of cyclic terpenoids, some of which are known to function as insect pheromones, $^{21}$ mycotoxins, and plant defense compounds. ${ }^{22}$ Fungal sesquiterpenoids have been shown, in a few cases, to contribute to the virulence of the fungi. ${ }^{23}$

A systematic manipulation of nutritional and environmental factors, altering cultivation parameters, media composition, temperature, etc., was carried out to induce the expression of silent biosynthetic pathways and the production of cryptic metabolites by this phytopathogenic fungus. This methodology could reveal potential new virulence or pathogenic factors.

Hence, along with other approaches, we undertook fermentation studies, following an "OSMAC" approach, ${ }^{18-20}$ of two wild type strains of Botrytis cinerea, B. cinerea UCA992 and B05.10, and the null double mutant from B05.10 strain, $B c B O T 2 \triangle B c B O A 6 \triangle .^{24}$ In the latter, the BcBOT2 and BcBOA6 genes, which encode the botrydial sesquiterpene cyclase (BcSTC1) and the polyketide synthase 6 (PKS6), have been inactivated, abolishing the production of the toxins: botrydial (1) and 3-acetylbotcinic acid (2) and botcinin A (2a) and their biosynthetic derivatives. $^{24}$

Thus, when the above strains were inoculated on plates containing a modified malt agar (MA) medium (see experimental) and sublethal amounts (5-30 ppm) of copper, a decrease in the weight of the extract obtained by extraction with ethyl acetate and morphological changes, principally a higher degree of melanization and conidiation, together with differences in the metabolic profile were observed. The strains were incubated at $25{ }^{\circ} \mathrm{C}$ under continuous full-spectrum light (day light) for 12 and 22 days (see Figure 2). Although

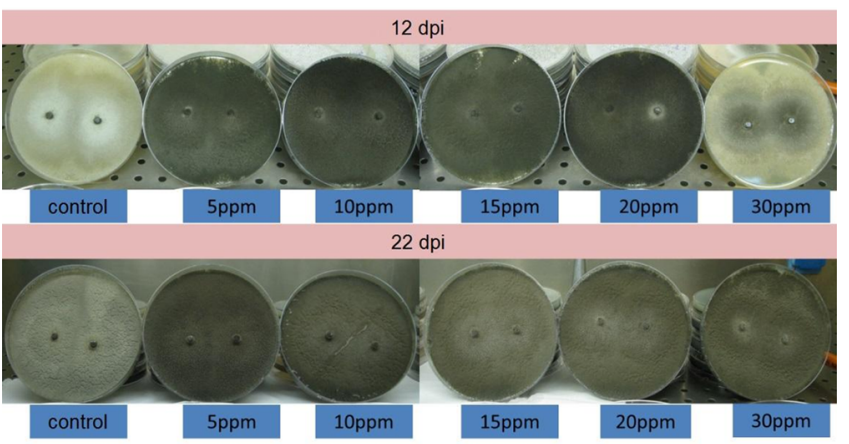

Figure 2. B. cinerea UCA992 growth in modified malt-agar (MA) medium with 0 to $30 \mathrm{ppm}$ of $\mathrm{CuSO}_{4}$.

morphological changes were observed in the three strains, the effects were specially marked in the strain B. cinerea UCA992, and they were visible for a long time. Figure 2 shows the appearance of the culture at 12 and 22 days post inoculation (dpi) for the cited strain B. cinerea UCA992.

Chromatographic purification of the metabolites from copper-containing cultures yielded a group of compounds, 
whose basic spectroscopic data were consistent with a sesquiterpenoid skeleton but structurally different from the classes of known secondary metabolites of $B$. cinerea, botrianes (1) and abscisic acid derivatives (3). The study of the extracts obtained from the broths of the three strains showed the presence of compounds 4-10 whose structures are shown in Figure 3. So, B. cinerea UCA992 yielded compounds 2a, 4-10; strain B05.10 compounds 2, 2a, 7, 8 and BcBOT2 $\triangle B c B O A 6 \Delta$ mutant compounds 6-10.
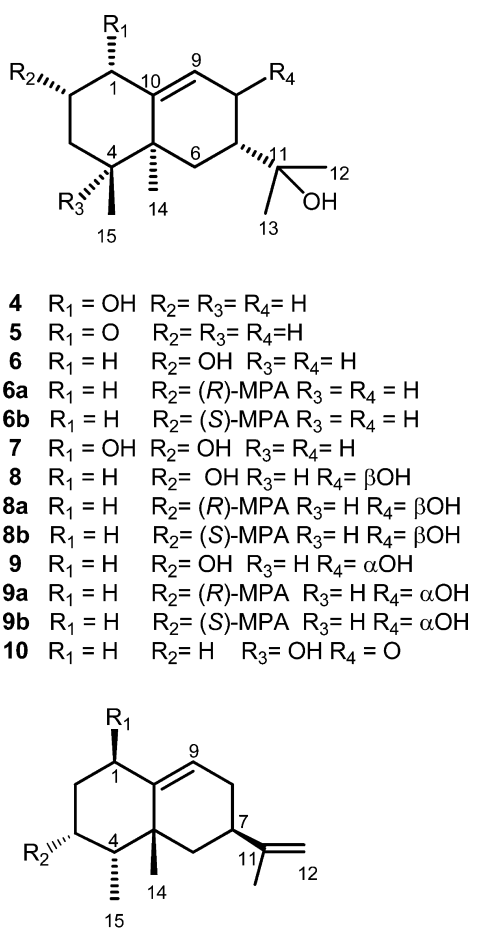

$11 \mathrm{R}_{1}=\mathrm{R}_{2}=\mathrm{OH}$

$12 \mathrm{R}_{1}=\mathrm{OH}, \mathrm{R}_{2}=\mathrm{H}$

$13 \quad R_{1}=O, R_{2}=H$

Figure 3. (+)-4-Epieremophilene derivatives isolated from B. cinerea strains and related compounds.

A preliminary study of each of the ${ }^{1} \mathrm{H}$ NMR spectra indicated that the spectroscopic data for structures 4-10 were similar to those described in the literature for the capsidiol and 3deoxycapsidiol derivatives $(\mathbf{1 1}, \mathbf{1 2}) .^{25,26}$ These are terpenoid compounds that accumulate in tobacco Nicotiana tabacum and chili pepper Capsicum annuum in response to fungal infection.

Compounds $\mathbf{4}$ and $\mathbf{5}$ were obtained as colorless oils, and they showed ions at their HRMS (ESI+) at $m / z=203.1783[\mathrm{M}+\mathrm{H}$ $\left.-2 \mathrm{H}_{2} \mathrm{O}\right]^{+}$and $237.1810[\mathrm{M}+\mathrm{H}]^{+}$consistent, respectively, with formulas $\mathrm{C}_{15} \mathrm{H}_{23}$ and $\mathrm{C}_{15} \mathrm{H}_{25} \mathrm{O}_{2}$, which, in turn, correspond to the loss of two molecules of $\mathrm{H}_{2} \mathrm{O}$ from a protonated molecular ion of formula $\mathrm{C}_{15} \mathrm{H}_{27} \mathrm{O}_{2}$ for compound $\mathbf{4}$ and to a protonated ion of formula $\mathrm{C}_{15} \mathrm{H}_{25} \mathrm{O}_{2}$ for compound 5. These molecular formulas are consistent with the observed ${ }^{13} \mathrm{C}$ NMR and DEPT data.

The ${ }^{1} \mathrm{H}$ NMR and ${ }^{13} \mathrm{C}$ NMR spectra for both compounds showed a characteristic pattern of signals of an eremophilene skeleton $(12,13)$. Compounds 4 and 5 showed signals characteristic of one proton on a trisubstituted double bond at $\delta 5.84$ and $6.58(1 \mathrm{H}, \mathrm{H}-9)$. There were signals from four methyl groups: two methyls on C-4 and C-5, at $\delta 0.93$ and 1.11 $(\mathrm{d}, J=7 \mathrm{~Hz}, 3 \mathrm{H})$ and at $\delta 1.35$ and $1.14(\mathrm{~s}, 3 \mathrm{H})$, respectively, and two singlet methyl groups at C-13 and C-12 $(\delta 1.17,1.18$ (compound 4) and $\delta 1.20,1.21$ (compound 5)), characteristic of a gem-dimethyl group attached to a hydroxylated carbon. All of these data were reminiscent of compounds 12 and 13 described by Coates et al., ${ }^{26}$ except for the signals in the ${ }^{1} \mathrm{H}$ and ${ }^{13} \mathrm{C}$ NMR corresponding to the isopropenyl group at C-7. The ${ }^{13} \mathrm{C}$ NMR spectrum confirmed the proposed structures for 4 and 5. Detailed analysis of ${ }^{1} \mathrm{H}-{ }^{1} \mathrm{H}$ homonuclear correlation spectroscopy (COSY), nuclear Overhauser effect spectroscopy (NOESY), and ${ }^{1} \mathrm{H}-{ }^{13} \mathrm{C}$ heteronuclear correlation spectroscopy spectra (HSQC and HMBC; Tables S1 and S2) led to the assignment of all the proton and carbon signals, confirming the relative stereochemistry and structures of 4-epieremophil-9-ene1,11-diol and 11-hydroxy-4-epieremophil-9-en-1-one, for compounds $\mathbf{4}$ and $\mathbf{5}$, respectively. Interestingly, the key NOE correlations were identical to those obtained for compounds $\mathbf{1 2}$ and 13, indicating that our compounds 4 and $\mathbf{5}$ shared the same relative stereochemistry. However, the optical rotation for compounds 4 and 5 were $+17.5\left(\mathrm{c} 0.1, \mathrm{CHCl}_{3}\right)$ and +25.4 (c $\left.0.13, \mathrm{CHCl}_{3}\right)$, respectively, while the values reported by Coates et al. were $-12.7\left(\mathrm{c} 0.71, \mathrm{CHCl}_{3}\right)$ and $-10.6\left(\mathrm{c} \mathrm{CHCl}_{3}\right)$. The opposite sign measured for our compounds, compared to those described in the literature, suggested that the basic structure of our compounds was enantiomeric to that described in the literature for the 3-deoxycapsidiol derivatives (12 and 13), leading to structures $\mathbf{4}$ and $\mathbf{5}$ indicated in Figure 3. Hence, these compounds had, from a stereochemical point of view, the basic structure of (+)-5-epiaristolochene, isolated from Aspergillus terreus, ${ }^{27}$ and they were named as $(1 S, 4 S, 5 S, 7 S)-4-$ epieremophil-9-ene-1 $\alpha, 11$-diol (4) and (4S, 5S, 7S)-11hydroxy-4-epieremophil-9-en-1-one (5).

Compound 6, $[\alpha]_{\mathrm{D}}^{25}+42.4^{\circ}$, was isolated as an oil whose molecular formula was established as $\mathrm{C}_{15} \mathrm{H}_{26} \mathrm{O}_{2}$ by HRMS and ${ }^{13} \mathrm{C} \mathrm{NMR}$, requiring three degrees of unsaturation. Its ${ }^{1} \mathrm{H} \mathrm{NMR}$ and ${ }^{13} \mathrm{C}$ NMR spectra were very similar to those of compound 4, except for the multiplicity observed, dddd, for the signal at $\delta$ 3.74 , on the carbon bearing the hydroxyl group, which was assigned to H-2. The pattern of signals in both spectra revealed the presence of secondary and tertiary hydroxyl groups, a double bond between $\mathrm{C} 9$ and $\mathrm{C} 10$, and four methyl groups. One methyl group signal appeared as a doublet, $J=7.6 \mathrm{~Hz}$, and the other methyl groups as three singlets. Analysis of COSY, NOESY, HSQC, and HMBC (Table S3) spectra led to the assignment of all the proton and carbon signals, confirming the relative stereochemistry and structure assigned to compound $\mathbf{6}$.

The previously proposed absolute configuration for this family of natural eremophilenol derivatives was studied for compound 6 using the Mosher NMR method. Compound 6 was treated with the $(R)-\alpha$-methoxy phenyl acetic acid $(R(-)$ MPA) and ( $S$ )- $\alpha$-methoxy phenyl acetic acid ( $S(+)$-MPA), separately, and $\mathrm{EDC}^{28}$ yielding the corresponding $(R)$ - and $(S)$ MPA esters, $\mathbf{6} \mathbf{a}$ and $\mathbf{6} \mathbf{b}$, respectively, to determine the absolute configuration of the carbon C-2. Comparison of the chemical shifts in ${ }^{1} \mathrm{H}$ NMR spectra of these two di-MPA esters showed a positive value for the $\Delta \delta^{R S}$ for the vicinal protons at C-1 $\left(\Delta \delta^{R S}[\mathrm{H}(1)]=\delta^{R}[\mathrm{H}(1)]-\delta^{S}[\mathrm{H}(1)]\right)(+0.14)$ and a negative value of $\Delta \delta^{R S}$ for H-3 (-0.29) and H-15 (-0.02). This indicated an $S$ configuration for $\mathrm{H}-2$ in compound 6. The stereochemistry of the rest of the chiral carbons was confirmed on the basis of NOE data (Table S3). Irradiation of the H-2 signal produced a NOE enhancement of the corresponding signal for $\mathrm{H}-1 \beta$ and $\mathrm{H}-15$, indicating a $\beta$ disposition of the 
methyl group at C-4. Furthermore, when the signal of the C-15 methyl group was irradiated, the signal of $\mathrm{H}-6 \beta$ was enhanced. Finally, irradiation of $\mathrm{H}-7$ and $\mathrm{H}-14$ gave a NOE enhancement with $\mathrm{H}-6 \beta$ and $\mathrm{H}-1 \alpha$, respectively, establishing the stereochemistry for these protons. The absolute stereochemistry of compound 6 was therefore established as $(2 S, 4 S, 4 a S, 6 R)-6-(2-$ hydroxypropan-2-yl)-4,4a-dimethyl-1,2,3,4,4a,5,6,7-octahydronaphthalene)-2-ol.

The ${ }^{1} \mathrm{H}$ NMR spectrum of compound $7,[\alpha]_{\mathrm{D}}^{28}+30.2^{\circ}$, showed, in addition to four methyl group signals at $\delta 0.96(\mathrm{~d}, J$ $=7.2 \mathrm{~Hz}), 1.31(\mathrm{~s}), 1.18(\mathrm{~s})$, and $1.17(\mathrm{~s})$, a pattern of signals characteristic of an eremophilenol derivative with two secondary hydroxyl groups. Compound 7 showed a molecular formula $\mathrm{C}_{15} \mathrm{H}_{26} \mathrm{O}_{3}$, obtained from the HRMS and corroborated by ${ }^{13} \mathrm{C}$ NMR data. The location of the hydroxyl groups in compound 7 at carbons $\mathrm{C}-1$ and $\mathrm{C}-2$ was established on the basis of their observed correlations in the COSY, HSQC, and HMBC (Table S4) experiments. The correlations in HMBC for $\mathrm{H}-1 / \mathrm{C}-9$, C-2, C-5, and C-3 confirmed the proposed structure. The stereochemistry was assigned by extensive NOESY experiments. $\mathrm{H}-1 \beta$ had correlation with $\mathrm{H}-9$ and $\mathrm{H}-2$, while $\mathrm{H}-2$ had a cross peak with $\mathrm{H}-1, \mathrm{H}-15, \mathrm{H}-3 \beta$, and $\mathrm{H}-3 \alpha$. Finally, the $\beta$ disposition for $\mathrm{H}-7$ was confirmed by the NOE enhancement produced on the $\mathrm{H}-15$ signal, while the $\alpha$ disposition for $\mathrm{H}-14$ was confirmed by irradiation of this proton and the observed enhancement of the $\mathrm{H}-4$ signal. The data above-described permitted us to propose an absolute stereochemistry as that shown in $7(1 R, 2 S, 4 S, 4 a S, 6 R)-6$-(2-hydroxypropan-2-yl)-4,4a-dimethyl-1,2,3,4,4a,5,6,7-octahydronaphthalene-1,2-diol.

Compounds 8 and $9,[\alpha]_{\mathrm{D}}^{20}+7.8^{\circ}$ and $[\alpha]_{\mathrm{D}}^{21}+88.1^{\circ}$, showed a characteristic and very similar signal pattern, indicating that both compounds had an eremophilene skeleton with two secondary hydroxyl groups but in different positions on the skeleton than those in the compound 7. Both compounds showed a molecular formula $\mathrm{C}_{15} \mathrm{H}_{26} \mathrm{O}_{3},[\mathrm{M}]^{+} 254$, corroborated by ${ }^{13} \mathrm{C}$ NMR data.

These compounds displayed correlations in COSY, HSQC, and HMBC experiments (Tables S5 and S6), from which it was inferred that the hydroxyl groups were situated at C-2 and C-8. The principal differences which were observed between their ${ }^{1} \mathrm{H}$ NMR spectra were the chemical shifts ( $\delta 4.24$ and 4.45 ), and the coupling constants for the signals corresponding to $\mathrm{H}-8$ $(J=9$ and $3 \mathrm{~Hz}, J=7.5$ and $1.5 \mathrm{~Hz}$ ), in compounds 8 and 9, respectively, indicating that they were epimeric at C-8.

The absolute stereochemistries of compounds $\mathbf{8}$ and $\mathbf{9}$ were deduced using the Mosher NMR method. Treatment of both compounds with $(R(-)-\mathrm{MPA})$ and $(S(+)-\mathrm{MPA})$, separately, and $\mathrm{EDC}^{28}$ gave the corresponding $(R)$ - and $(S)$-MPA esters on C-2, compounds $8 \mathbf{a}$ and $9 \mathbf{a}$ and compounds $8 \mathbf{b}$ and $9 \mathbf{b}$, respectively. Unfortunately the MPA esters of the hydroxyl group at C-8 could not be obtained. Comparison of the chemical shifts in ${ }^{1} \mathrm{H}$ NMR spectra of the two couples of MPA esters showed a positive value of $\Delta \delta^{R S}$ for vicinal protons in C-1 $\left(\Delta \delta^{R S}[\mathrm{H}(1)]=+0.14\right)$ while the negative value of $\Delta \delta^{R S}$ for $\mathrm{H}-3$ $(-0.13)$ and $\mathrm{H}-15(-0.02)$ indicated an $S$ configuration for $\mathrm{H}-2$ in compound 8 . In the same context, compound 9 showed $\Delta \delta^{R S}[\mathrm{H}(1)]=+0.13$ and negative values of $\Delta \delta^{R S}$ for $\mathrm{H}-3$ $(-0.11)$ and $\mathrm{H}-15(-0.02)$ indicating, again, an $S$ configuration for $\mathrm{H}-2$. The stereochemistry of the remaining chiral carbons was confirmed on the basis of NOE experiments (Tables S5 and S6).
Hence, irradiation of the $\mathrm{H}-2$ signal of compound 8 produced NOE enhancement of corresponding signals for $\mathrm{H}$ $1 \beta$ and $\mathrm{H}-15$, indicating a $\beta$ disposition for $\mathrm{H}-2$. Furthermore, when the signal of the $\mathrm{H}-15$ (methyl group) was irradiated, the signals of $\mathrm{H}-6 \beta, \mathrm{H}-7 \beta, \mathrm{H}-3 \beta$, and $\mathrm{H}-2 \beta$ were enhanced. Finally, the stereochemistry for $\mathrm{H}-8 \alpha$ was assigned by NOE interaction with $\mathrm{H}-6 \alpha, \mathrm{H}-9$, and $\mathrm{H}-13$, respectively.

On the other hand, irradiation of $\mathrm{H}-15 \beta$ (methyl group), in compound 9, produced NOE enhancement of corresponding signals of $\mathrm{H}-6 \beta, \mathrm{H}-7 \beta, \mathrm{H}-3 \beta$, and $\mathrm{H}-2 \beta$. Interestingly, in accordance with the stereochemistry shown in structure 9, when the signal for $\mathrm{H}-7 \beta$ was irradiated, the signals of $\mathrm{H}-8, \mathrm{H}-$ $15, \mathrm{H}-13$, and $\mathrm{H}-12$ were enhanced.

The absolute stereochemistry of compounds 8 and 9 was determined as $(2 S, 4 S, 4 a S, 6 R, 7 R)-6$-(2-hydroxypropan-2-yl)4,4a-dimethyl-1,2,3,4,4a,5,6,7-octahydronaphthalene-2,7-diol (8) and (2S,4S,4aS,6R,7S)-6-(2-hydroxypropan-2-yl)-4,4a-dimethyl-1,2,3,4,4a,5,6,7-octahydronaphthalene-2,7-diol (9)

The molecular formula of compound 10, $[\alpha]_{\mathrm{D}}^{30}+27.2^{\circ}$, was determined by HRMS as $\mathrm{C}_{15} \mathrm{H}_{24} \mathrm{O}_{3}$. The ${ }^{13} \mathrm{C}$ NMR revealed the presence of four methyl, four methylene, and two methine groups and five quaternary carbons, one of them corresponding to a ketone at $\delta 202.9 \mathrm{ppm}$. Furthermore, the ${ }^{1} \mathrm{H}$ NMR spectrum of 10 showed, in addition to signals for four methyl groups, a singlet, at $\delta 1.22,1.23,1.27$ and 1.37, a pattern of signals that were characteristic of an eremophilenol derivative with two tertiary hydroxyl groups on C-4 and C-11. Furthermore, the pattern of signals in both spectra indicated the presence of an $\alpha, \beta$ unsaturated ketone with the double bond between $\mathrm{C} 9$ and $\mathrm{C} 10$. The proposed structure 10 was supported on the basis of the observed correlations in the COSY, HSQC, and HMBC (Table S7) spectra. The stereochemistry was assigned by an extensive NOESY experiment. Irradiation of $\mathrm{H}-15 \beta$ produced NOE enhancements of the corresponding signals of $\mathrm{H}-2 \beta, \mathrm{H}-3 \beta, \mathrm{H}-6 \beta$, and $\mathrm{H}-7 \beta$, while irradiation of $\mathrm{H}-14 \alpha$ produced a NOE effect at $\mathrm{H}-1 \alpha, \mathrm{H}-3 \alpha$, and $\mathrm{H}-6 \alpha$. These data were in accord with the structure and stereochemistry shown for compound in $\mathbf{1 0 .}$

These results indicate that the presence of sublethal amounts of copper in the medium broth promotes the production of a new family of sesquiterpenes with a basic structure of (+)-5epiaristolechene. The induction of these cryptic metabolites by copper was more pronounced in the B.c. UCA992 strain and less intense in B05.10. On the other hand, the induction of this silent biosynthetic pathway must be accompanied by the overexpression of the corresponding sesquiterpene cyclase involved in the eremophilene biosynthesis.

Expression Profiles of Sesquiterpene Cyclases Encoding Genes during Fermentation. Real-Time PCR Optimization. A total of eight specific pairs of primers were designed in this study; five of them were specific for the genes encoding the sesquiterpene cyclase in B. cinerea B05.10 and three pairs for specific amplification of housekeeping genes: actin, $\beta$-tubulin, and EF- $1 \alpha$ (Supporting Information Table S8). Actin and $\beta$-tubulin genes are commonly used for normalization of expression results by RT-qPCR in B. cinerea and other fungi. ${ }^{29} \mathrm{EF}-1 \alpha$ gene codifies for a ubiquitous protein that binds aminoacyl-tRNA to ribosomes during protein synthesis. ${ }^{30}$ It was also included as a third normalization gene, showing a stable pattern of expression during the fermentation.

Conventional PCR confirmed the correct specificity and selectivity of each pair of primers, using genomic DNA or cDNA as a template. For real-time PCR amplification, optimal 

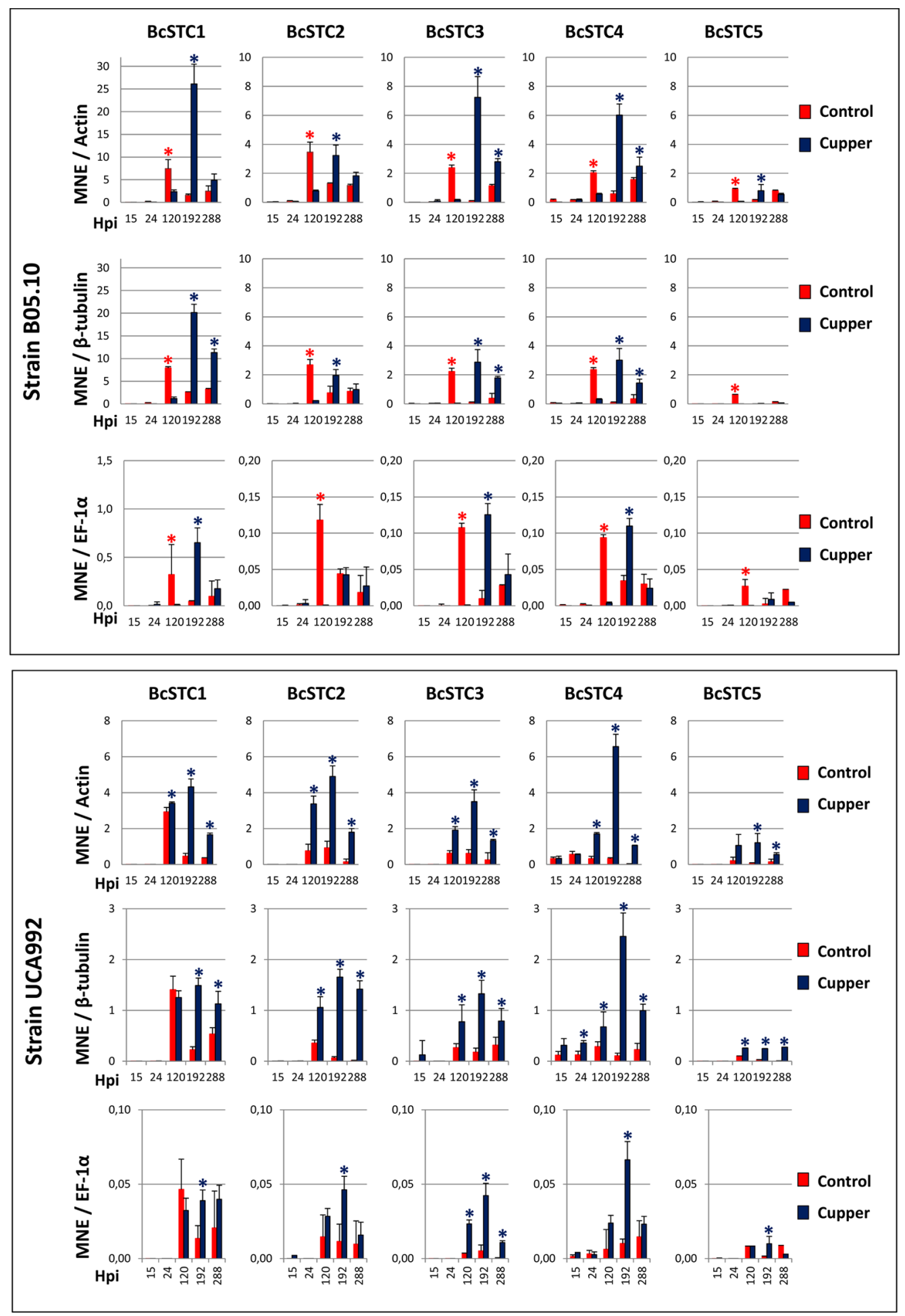

Figure 4. Expression profiles of BcSTC genes in strain B05.10 and UCA992 during fermentation with and without supplement of copper. MNE: Mean Normalized Expression using actin, $\beta$-tubulin and EF-3 as housekeeping genes. Hpi: hours post inoculation.

primer concentrations and annealing temperature were established and set at $200 \mathrm{nM}$ and $60^{\circ} \mathrm{C}$, respectively, except for the EF-1 $\alpha$ gene, whose annealing temperature was set at 56 ${ }^{\circ} \mathrm{C}$ as an optimum value. Standard curves were constructed by serial dilution of cDNA samples, and linear regression data demonstrated good efficiencies for all the genes used (Table S8). Mean normalized expression was calculated according to Gil-Salas et al. ${ }^{31}$ Actin, $\beta$-tubulin, and EF- $1 \alpha$ showed a stable expression level during fermentation assays, but the level of expression was different between them. EF-1 $\alpha$ showed a higher level of expression in all samples, and for this reason MNE values normalized with this gene are lower than those MNEs normalized with actin or $\beta$-tubulin gene expression, although expression profiles are the same with the three housekeeping genes that were used.

BCSTC Encoding Genes Expression Profiles. Fermentations with and without copper were studied, and mycelium samples were taken between 15 and $288 \mathrm{~h}$ post inoculation (hpi). 
Results showed a main effect, common for both strains: the delay of the BcSTC genes' maximum expression levels from 120 hpi (control fermentation) to $192 \mathrm{hpi}$ (Figure 4). But, the analysis in detail along five BcSTC genes in B05.10 and UCA992 strains was different, in accord with the metabolic pattern, which they showed.

In strain B05.10, the BcSTC1 was expressed 2.6-fold and 4.91-fold greater than the other BcSTC genes during both the control and copper supplemented fermentations, respectively. Interestingly, the expression at $192 \mathrm{hpi}$ in the copper fermentation was 2.7 times higher than in the control fermentation (Figure 4). The effect of the presence of copper on the expression of the BcSTC3 and BcSTC4 genes was very interesting. During a copper fermentation of strain B05.10, the level of expression of BcSTC4 and BcSTC3 at 192 hpi increased. This rise is significantly different when it was compared with the rest of the BcSTC genes expression levels, but there was no significant difference between both genes in strain B05.10.

Strain UCA992 expresses all the BcSTC genes at a lower level than B05.10 during the control fermentation. The presence of copper significantly increased all the levels of expression of the $B c S T C$ genes at 120,192 , and $288 \mathrm{hpi}$, but the most remarkable effect was observed for BcSTC4. This gene showed the highest level of expression in UCA992 at $192 \mathrm{hpi}$, being significantly different when compared to the levels of expression of the rest $B c S T C$ genes which were studied.

Role of Eremophilenols in the Life Cycle of Botrytis. Throughout the various stages of their life cycle, microorganisms secrete molecules whose function is to convey information about environmental conditions or status of the cells within the colony, thus ensuring a coordinated response. $^{33,34}$

In a review of the literature on the role assigned to different secondary metabolites in fungi, and their role in the selfregulating signaling processes, we observed that some compounds with eremophilene skeleton showed sporogenic activity including esporogen AO1 isolated from Aspergillus oryzae and sporogen PF-1, isolated from Penicillium funiculosum. $^{35}$

This information, together with the effect observed in the cultures supplemented with copper, in which a greater melanization and conidiation was detected, and the fact that isolated eremophilenol was obtained from 12 to 22 days old cultures, when conidiation began, led us to propose that this family of metabolites was involved in the conidiation process of the fungus $B$. cinerea.

The conidiation cellular mechanisms have been widely studied in Aspergillus nidulans and Neurospora crassa. ${ }^{36,37}$ However, the precise mechanism by which conidiation induction is unleashed under such complex environmental changes for the hypha has proven to be an elusive question.

In order to obtain data that could reveal the role played by these metabolites in the secondary metabolism of the plant pathogenic fungus, conidiation-inducing activity experiments were conducted, with those metabolites 6-8 isolated in major amounts, aimed at determining their biological function.

Consequently, B. cinerea UCA992 and B05.10 strains were incubated on MA and MM media. Each Petri dish was inoculated with mycelium on one small slice of agar $(1 \mathrm{~cm})$. After $30 \mathrm{~h}$, a solution in methanol $(10 \mu \mathrm{L})$, containing a mixture of compounds $6-8$, at a rate of $1,25 \mathrm{mg} \mathrm{mL}^{-1}$ each, was added to each plate over the fungus mycelium. The control dishes were treated with $10 \mu \mathrm{L}$ of methanol.
In general, an increase in the formation of conidiophores was observed on those plates to which the eremophilenol mixture had been added compared to the controls in both MM and MA media. Interestingly, conidiation started before and conidiophores were formed in greater numbers, in plates with MA medium. The plates were monitored every $24 \mathrm{~h}$ by setting the most suitable time for quantitative analysis of conidiation.

Thus, after $168 \mathrm{~h}$ post-treatment (hpt), the number of conidia was counted, in both controls and treated plates with eremophilenol derivatives. Results obtained by counting conidia in a treated culture of B. cinerea B05.10 and UCA992 with compounds 6-8 showed that in all of the treatments containing eremophilene derivatives, a higher conidiation occurs. This effect, when compared with the controls, was greater in the strain B. cinerea B05.10 than in the strain $B$. cinerea UCA992, being 5-6-fold and 3-fold higher, respectively (Figure 5 and Supporting Information Table S9).

These results lead us to conclude that the new eremophilenols excreted by $B$. cinerea are involved in conidiation and appear to be involved in self-regulation of the production of asexual spores.
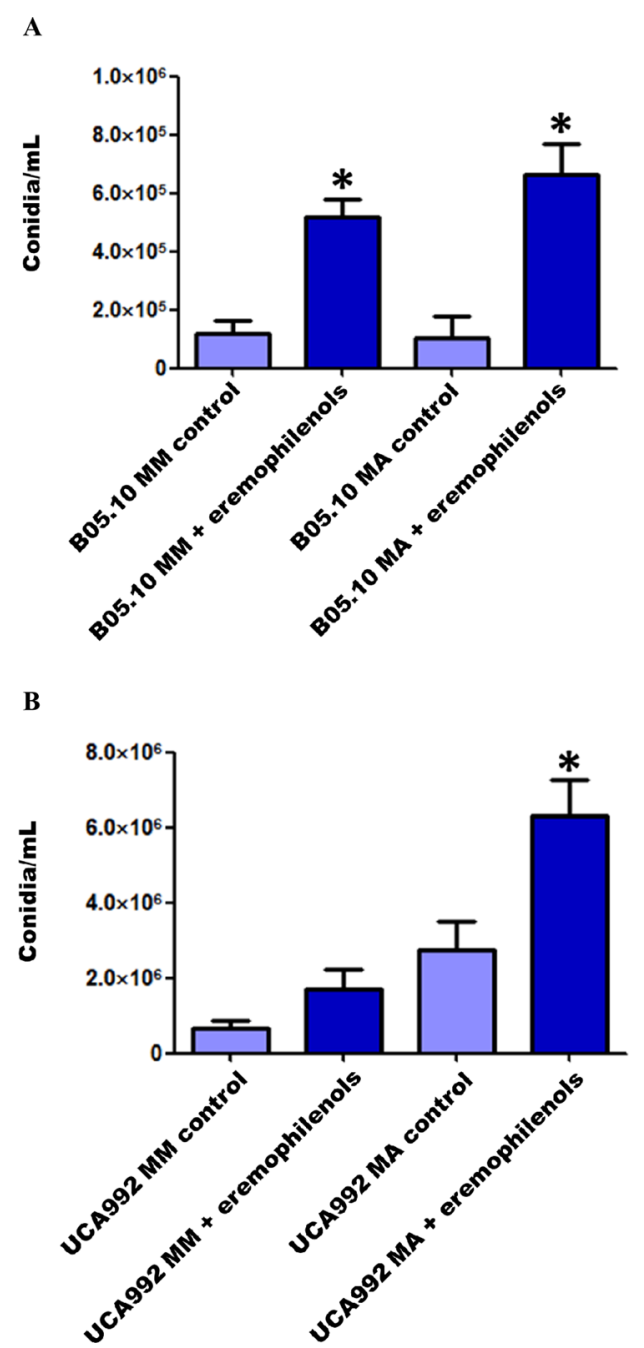

Figure 5. Effect of eremophilenol derivatives 6-8 (A) on conidiation in B05.10, (B) on conidiation in B. cinerea UCA992 cultures, in minimal media (MM) and malt-agar (MA). Values are expressed as the means \pm standard deviations of three independent experiments. *Data with differences statistically significant $(p<0.05)$. 
When the Petri dishes used in the conidiation assay were observed, $24 \mathrm{hpt}$, with an inverted microscope, an interesting accumulation of axial hyphaes and extensive hyphal branching were observed. These yielded an important number of multicellular appressorial structures which could be observed in large numbers after $48 \mathrm{hpt}$ (Figures 6 and 7). These infection structures are referred to as complex appressoria or infection cushions, and they are commonly seen in $B$. cinerea growing against hard surfaces. ${ }^{38,39}$

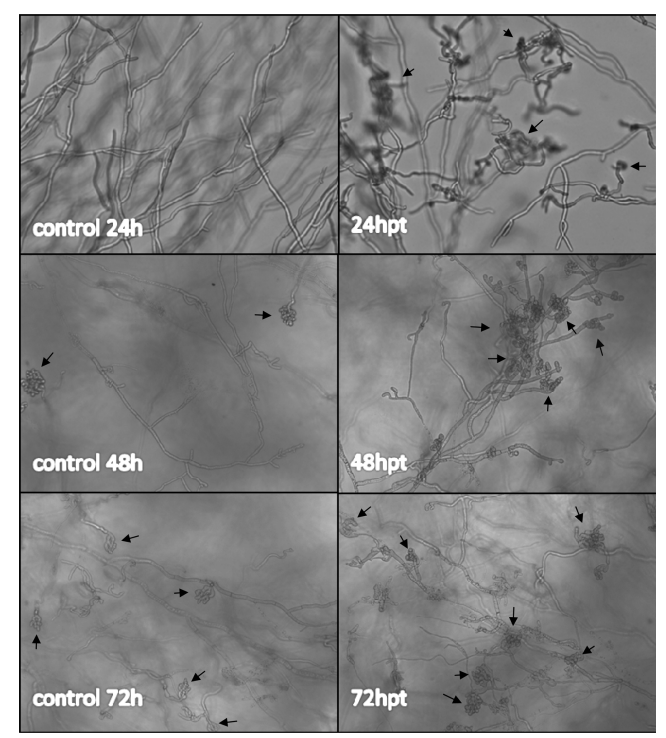

Figure 6. Effect of eremophilenol derivatives 6-8 in methanol $(1,25$ $\left.\mathrm{mg} \mathrm{mL}^{-1}\right)$, on B05.10 strain culture in MM medium. Control dishes were treated with $10 \mu \mathrm{L}$ of methanol.

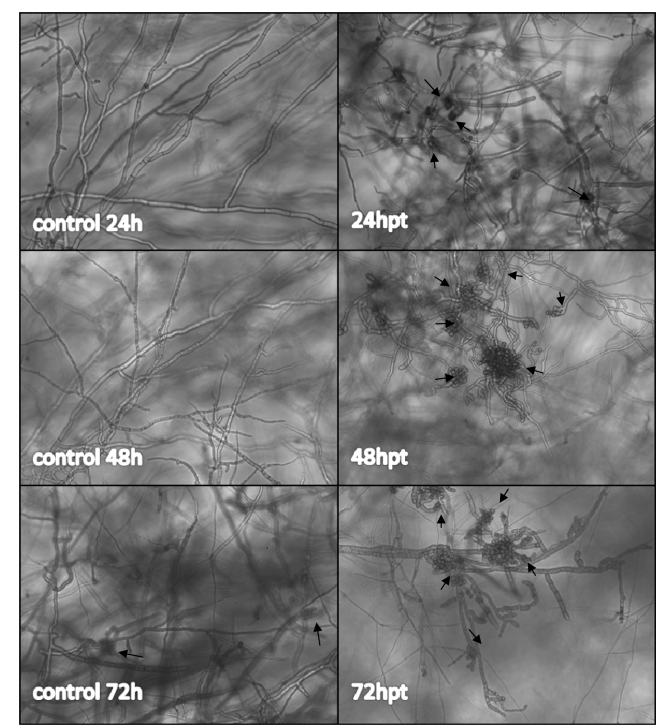

Figure 7. Effect of eremophilenol derivatives 6-8, in methanol $(1,25$ $\mathrm{mg} \mathrm{mL} \mathrm{m}^{-1}$ ), on B. cinerea UCA992 culture in MM media. Control dishes were treated with $10 \mu \mathrm{L}$ of methanol.

An appressorium is an infection structure that adheres to host surfaces, is typically formed prior to host penetration, and is a prerequisite to infection for many pathogenic fungi. ${ }^{39}$ Appressorium differentiation is triggered by different signals in different species of phytopathogenic fungi, and the substrate attachment appears to be a prerequisite for appressorium formation in all fungi. ${ }^{40}$ In many cases, the hydrophobicity of contact surfaces is sufficient to trigger appressorium formation. ${ }^{41}$ However, little is known about the exogenous and endogenous signals regulating this important developmental process. The mechanisms of surface recognition and signal transduction regulating infection structures formation in phytopathogenic fungi await further investigation, and they are not only of considerable biological interest but could also provide targets for the development of novel disease control strategies.

Figures 6 and 7 show photographs of the control and inoculated plates with the above indicated concentration of eremophilenol derivatives, for both strains, after 24,48 , and 72 hpt with compounds 6-8.

The photographs clearly showed differences in the formation of infection structures during treatments yielding more infection cushions or complex appressoria when compared with their respective controls. The presence of derivatives of (+)-4-epieremophil-9-en-11-ol (6-8) in the culture medium, could play a role during promotion and formation of these complex appressoria. This effect seems to be greater in the strain B. cinerea UCA992 than in the strain B05.10.

These results lead us to conclude that the new eremophilenols, in addition to the conidiation (discussed above), promote and could regulate the production of complex appressoria. To our knowledge, this is the first time that the regulation of the infection cushions production by sesquiterpeoid metabolites is reported.

\section{METHODS}

Strains and Culture Conditions. Three strains were used: wild types B. cinerea UCA992, B05.10, and the double mutant B05.10$B c B O T 2 \triangle B c B O A 6 \Delta .{ }^{24}$ B. cinerea UCA992 was obtained from grapes from the Domecq vineyard, Jerez de la Frontera, Cádiz, Spain. This culture is deposited in the Universidad de Cádiz, Mycological Herbarium Collection (UCA). B05.10 and double mutant B05.10$B c B O T 2 \triangle B c B O A 6 \Delta^{24}$ were supplied by Dr. Muriel Viaud of the UMR-BIOGER, INRA (Grignon, France). B. cinerea strains were grown on PDA medium at $24{ }^{\circ} \mathrm{C}$ with $24 \mathrm{~h}$ of daylight for culturing. They were grown in Roux culture bottles $(200 \mathrm{~mL})$ containing 150 $\mathrm{mL}$ of modified Czapek-Dox medium (30 $\mathrm{mg}$ glucose, $1 \mathrm{~g}$ yeast extract, $1 \mathrm{~g} \mathrm{~K}_{2} \mathrm{HPO}_{4}, 2.5 \mathrm{~g} \mathrm{NaNO}_{3}, 0.5 \mathrm{~g} \mathrm{MgSO}_{4} \cdot 7 \mathrm{H}_{2} \mathrm{O}, 0.001 \mathrm{~g}$ $\mathrm{FeSO}_{4} \cdot 7 \mathrm{H}_{2} \mathrm{O}, 0.5 \mathrm{~g} \mathrm{KCl}, 0.005 \mathrm{~g} \mathrm{CuSO}_{4} \cdot 5 \mathrm{H}_{2} \mathrm{O}$, at a pH of $7,1 \mathrm{~L}$ of water). Bottles were inoculated with $2 \times 10^{7}$ fresh conidia and incubated for 27 days at $24-26{ }^{\circ} \mathrm{C}$ on static under daylight for metabolite production. For gene expression analysis, mycelia from B05.10 and UCA992 were harvested at 15, 24, 120, 192, and $288 \mathrm{hpi}$. Samples were immediately frozen in liquid nitrogen until use. Fermentations were carried out per triplicate using independent conidia samples for inoculation.

Botrytis cinerea Cultures on Malt-Agar with $0-30$ ppm of $\mathrm{Cu}$. Petri discs containing malt agar medium (MA; 20 g glucose, $20 \mathrm{~g}$ malt extract, $20 \mathrm{~g}$ agar, and $1 \mathrm{~g}$ peptone, per liter of water, $\mathrm{pH}$ 6.5-7) were supplemented with increasing amounts of $\mathrm{CuSO}_{4} \cdot 5 \mathrm{H}_{2} \mathrm{O}$ reaching concentrations between 0 and $30 \mathrm{ppm}$ of copper. Plates were inoculated and incubated at $25{ }^{\circ} \mathrm{C}$, under a continuous full-spectrum daylight lamp, for 12 and 22 days (Figure 2). The medium was extracted with ethyl acetate and morphological changes observed by microscopy. The experiments were performed in triplicate.

Extraction and Isolation of Metabolites. The broths, $3 \mathrm{~L}$, from each of the strains, B. cinerea UCA992, B05.10, and BcBOT2 $\Delta B c$ $B O A 6 \Delta$, were saturated with $\mathrm{NaCl}$ and extracted with ethyl acetate $(\times 4)$. The organic extracts were washed with $\mathrm{H}_{2} \mathrm{O}(\times 3)$ and then dried over anhydrous $\mathrm{Na}_{2} \mathrm{SO}_{4}$. Evaporation of the solvent at reduced pressure gave extracts as yellow oils, $200 \mathrm{mg}$ (from B. cinerea UCA992), $160 \mathrm{mg}$ (B05.10), and $180 \mathrm{mg}$ (BcBOT2 $\triangle B c B O A 6)$. 
A preliminary fractionation of the extracts was achieved by column chromatography eluting with petroleum ether: ethyl acetate mixtures containing increasing percentages of ethyl acetate $(10-100 \%)$. Final purification of interesting fractions was carried out by means of semipreparative HPLC: hexane-ethyl acetate-acetone 70:20:10, at a flow of $2.5 \mathrm{~mL} \mathrm{~min}{ }^{-1}$.

The broth of $B$. cinerea UCA992 gave compounds $2 \mathrm{a}(1.1 \mathrm{mg}), 4$ $(0.95 \mathrm{mg}), 5(1.12 \mathrm{mg}), 6$ (5.17 mg), 7 (3.09 mg), 8 (3.04 mg), 9 (3.14 mg), and $10(0.85 \mathrm{mg})$.

Strain B05.10 broth afforded compounds $2(4.67 \mathrm{mg}), 2 \mathrm{a}(2.5 \mathrm{mg})$, $7(2.3 \mathrm{mg})$, and $8(1 \mathrm{mg})$.

And finally the double mutant $B c B O T 2 \triangle B c B O A 6 \Delta$ gave $6(2.75$ $\mathrm{mg}), 7(4.17 \mathrm{mg}), \mathbf{8}(6.68 \mathrm{mg}), \mathbf{9}(1.88 \mathrm{mg})$, and $10(0.22 \mathrm{mg})$. The IR, NMR, and MS data for compounds 4-10 are available in the Supporting Information.

(+)-4-Epieremophil-9-ene-1 $\alpha, 11$-diol (4). Colorless oil. $[\alpha]_{\mathrm{D}}^{21}+$ $17.5^{\circ}$ (c 0.1, $\mathrm{CHCl}_{3}$ ). HRMS (ESI) $\mathrm{m} / \boldsymbol{z}$ calcd for $\mathrm{C}_{15} \mathrm{H}_{23}\left[\mathrm{M}^{+}-\right.$ $\left.2 \mathrm{H}_{2} \mathrm{O}+\mathrm{H}\right] 203.1800$, found 203.1783 .

(+)-11-Hydroxy-4-epieremophil-9-en-1-one (5). Colorless oil. $[\alpha]_{\mathrm{D}}^{21}+25.4^{\circ}\left(c \quad 0.13, \mathrm{CHCl}_{3}\right)$. HRMS (ESI) $\mathrm{m} / \boldsymbol{z}$ calcd for $\mathrm{C}_{15} \mathrm{H}_{25} \mathrm{O}_{2}\left[\mathrm{M}^{+}+\mathrm{H}\right]$ 237.1855, found 237.1810.

(+)-4-Epieremophil-9-en-2 $\alpha, 11$-diol (6). Colorless oil. $[\alpha]_{\mathrm{D}}^{25}+$ $42.4^{\circ}\left(0.5 \mathrm{c}, \mathrm{CHCl}_{3}\right)$. HRMS $\boldsymbol{m} / \boldsymbol{z}$ calcd for $\mathrm{C}_{15} \mathrm{H}_{26} \mathrm{O}_{2}\left[\mathrm{M}^{+}\right]$ 238.1933, found 238.1950.

(+)-4-Epieremophil-9-ene-1 $\alpha, 2 \alpha, 11$-triol (7). Colorless oil. $[\alpha]_{\mathrm{D}}^{28}+$ $30.2^{\circ}\left(c 0.2, \mathrm{CHCl}_{3}\right)$. HRMS (ESI) $\boldsymbol{m} / \boldsymbol{z}$ calcd for $\mathrm{C}_{15} \mathrm{H}_{26} \mathrm{O}_{3} \mathrm{Na}\left[\mathrm{M}^{+}+\right.$ $\mathrm{Na}$ ] 277.1780, found 277.1769.

(+)-4-Epieremophil-9-en-2 $\alpha, 8 \beta, 11$-triol (8). Colorless oil. $[\alpha]_{\mathrm{D}}^{20}+$ $7.8^{\circ}\left(c 0.2, \mathrm{CHCl}_{3}\right.$ ). HRMS (ESI) $m / z$ calcd for $\mathrm{C}_{15} \mathrm{H}_{26} \mathrm{O}_{3} \mathrm{Na}\left[\mathrm{M}^{+}+\right.$ $\mathrm{Na}$ ] 277.1780, found 277.1772.

(+)-4-Epieremophil-9-en-2 $\alpha, 8 \alpha, 11$-triol (9). Colorless oil. $[\alpha]_{\mathrm{D}}^{21}+$ 88.1 $1^{\circ}\left(c 0.3, \mathrm{CHCl}_{3}\right)$. HRMS (ESI) $m / z$ calcd for $\mathrm{C}_{15} \mathrm{H}_{26} \mathrm{O}_{3} \mathrm{Na}\left[\mathrm{M}^{+}+\right.$ $\mathrm{Na}]$ 277.1780, found 277.1790.

(+)-4 $\alpha, 11$-Dihydroxy-4-epieremophil-9-en-8-one (10). $[\alpha]_{\mathrm{D}}^{30}+$ $27.2^{\circ}\left(0.2 \mathrm{c}, \mathrm{CHCl}_{3}\right)$. HRMS $\boldsymbol{m} / \boldsymbol{z}$ calcd for $\mathrm{C}_{15} \mathrm{H}_{24} \mathrm{O}_{3}\left[\mathrm{M}^{+}\right]$ 252.1725, found 277.1740.

Determination of Absolute Configuration. Mosher's Esters: General Procedure. The determination of the absolute configuration of compounds 6,8 , and 9 was carried out by Riguera's variabletemperature NMR method, ${ }^{28}$ using Mosher's esters. The preparation of $(R)$ - and (S)-methoxyphenylacetic acid (MPA) esters 6a, 8a, and 9a and $6 b, 8 b$, and $9 b$, were performed, from compounds 6,8 , and 9 , by the reported procedure. ${ }^{28}$ The NMR data for esters $6 a, 8 a$, and $9 a$ and $\mathbf{6 b}, \mathbf{8 b}$, and $\mathbf{9 b}$ are available in the Supporting Information.

Specific Primers Design for Sesquiterpene Cyclases Encoding Gene. In the genome sequence of strains B05.10, five genes encoding STC enzymes are found; ${ }^{5} \beta$-tubulin, actin, and EF- $1 \alpha$ genes were also selected as the most stable candidate gene for normalization. DNAStar software was used for specific primer design (Supporting Information Table S8). Genomic DNA samples were extracted from both strains B05.10 and UCA992 using a protocol described by Garrido et al. ${ }^{42}$ Conventional PCR reactions and gel electrophoresis were carried using each pair of specific primers designed in this study for cheking their specificity.

RNA Extraction and RT-qPCR Assays. Frozen mycelium per sample was homogenized in a $2 \mathrm{~mL}$ tube containing $450 \mathrm{mg}$ of glass beads (Sigma-Aldrich), two 1/4-CeramicSpheres (Q-Biogene), and 1 $\mathrm{mL}$ of Trizol (Invitrogen) and using a Fast-Prep Instrument (MP Biomedicals). Then, RNA samples were extracted as described by Froehlich et al. ${ }^{43}$ RNA was purified using RQ1 RNase-Free DNase (Promega), and total RNA purity and concentration were determined using a NanoDrop 2000c spectrophotometer (Thermo-Scientific). Gel electrophoresis was performed to verify intact RNA. For quantitative RT-qPCR expression analyses, $1 \mu \mathrm{g}$ of RNA of each sample was reverse-transcribed into cDNA using a DyNAmo cDNA Synthesis Kit (Thermo-Scientific) according to standard protocols. Control reactions were performed without reverse transcriptase to verify the absence of gDNA contamination.

Real-time PCR amplifications were carried out using the CFX96 Touch Real-Time PCR Detection System (BioRad) and Maxima
SYBRGreen qPCR MasterMix (Thermo-Scientific) following the manufacturer's instructions. Primer concentrations were optimized creating a $4 \times 4$ four matrix of reactions, ranging from 100 to $400 \mathrm{nM}$ for each primer against different concentrations of the partner primer. Annealing temperatures were optimized from 56 to $62{ }^{\circ} \mathrm{C}$. Amplification conditions were composed of an initial step for enzyme activation at $50{ }^{\circ} \mathrm{C}$ for $3 \mathrm{~min}$, a denaturalization step at $95{ }^{\circ} \mathrm{C}$ for 10 min, 45 cycles at $95{ }^{\circ} \mathrm{C}$ for $15 \mathrm{~s}$, and a gradient of $56-60{ }^{\circ} \mathrm{C}$ for $1 \mathrm{~min}$. Melting curve analysis was set up from 65 to $95^{\circ} \mathrm{C}$, at increments of $0.2{ }^{\circ} \mathrm{C}$ for $5 \mathrm{~s}$, and the plate read. Gel electrophoresis was performed to confirm specificity of the product during optimization. Relative transcriptomic expressions of the STC genes were statistically analyzed using methods from Gil-Salas et al. ${ }^{31}$ All tests were carried out in triplicate and in three separate experiments.

Bioassay of the Conidiation-inducing Eremophilenes. A sporulation induction bioassay was carried out on solid agar cultures. One week old, $1-\mathrm{cm}$-diameter mycelial plugs of actively growing $B$. cinerea UCA992 and B05-10 were placed in the center of Petri plates $(15 \mathrm{~cm})$ with malt agar (MA) medium or minimal medium (MM; $2 \mathrm{~g}$ malt extract, $20 \mathrm{~g}$ agar, per liter of water, $\mathrm{pH}$ 6.5-7). Negative controls were performed with the medium and the fungi strains.

After $30 \mathrm{~h}, 10 \mu \mathrm{L}$ of a solution in methanol, containing a mixture of compounds 6-8, at a rate of $1.25 \mathrm{mg} \mathrm{mL}^{-1}$ each, was added to each plate over the fungus mycelium. The control dishes were treated with $10 \mu \mathrm{L}$ of methanol. The colonies were then observed with a binocular microscope after $24,48,72,96,110 \mathrm{~h}$ of the addition of the solution. The experiments were performed in triplicate.

Furthermore, conidia were counted after $168 \mathrm{hpt}$. A total of $1 \mathrm{~mL}$ of distilled and deionized water was added to the plates, and conidia were separated from fungal mycelium by a bacteriological loop. The numbers of spores were counted in a conidia water suspension in a Neubauer chamber. The average conidia per milliliter and standard error of the mean (SEM) are present in Table S9.

\section{ASSOCIATED CONTENT}

\section{Supporting Information}

The Supporting Information is available free of charge on the ACS Publications website at DOI: 10.1021/acschembio.5b00931.

Details of general experimental procedures, characterization data, and reproductions of ${ }^{1} \mathrm{H}$ and ${ }^{13} \mathrm{C}$ NMR spectra (PDF)

\section{AUTHOR INFORMATION}

\section{Corresponding Author}

*E-mail: isidro.gonzalez@uca.es.

\section{Author Contributions}

${ }^{\perp}$ These authors contributed equally to this work.

Notes

The authors declare no competing financial interest.

\section{ACKNOWLEDGMENTS}

This research was supported by a grant from MINECOFEDER (AGL2012-39798-C02-01, -02).

\section{REFERENCES}

(1) Wilkinson, B., and Micklefield, J. (2007) Mining and engineering natural-product biosynthetic pathways. Nat. Chem. Biol. 3, 379-86.

(2) Bentley, S. D., Chater, K. F., Cerdeño-Tárraga, A.-M., Challis, G. L., Thomson, N. R., James, K. D., Harris, D. E., Quail, M. A., Kieser, H., Harper, D., Bateman, A., Brown, S., Chandra, G., Chen, C. W., Collins, M., Cronin, A., Fraser, A., Goble, A., Hidalgo, J., Hornsby, T., Howarth, S., Huang, C.-H., Kieser, T., Larke, L., Murphy, L., Oliver, K., O’Neil, S., Rabbinowitsch, E., Rajandream, M., Rutherford, K., Rutter, S., Seeger, K., Saunders, D., Sharp, S., Squares, R., Squares, S., Taylor, K., Warren, T., Wietzorrek, A., Woodward, J., Barrell, B. G., Parkhill, J., 
and Hopwood, D. A. (2002) Complete genome sequence of the model actinomycete Streptomyces coelicolor A3(2). Nature 417, 141-147.

(3) Omura, S., Ikeda, H., Ishikawa, J., Hanamoto, a, Takahashi, C., Shinose, M., Takahashi, Y., Horikawa, H., Nakazawa, H., Osonoe, T., Kikuchi, H., Shiba, T., Sakaki, Y., and Hattori, M. (2001) Genome sequence of an industrial microorganism Streptomyces avermitilis: deducing the ability of producing secondary metabolites. Proc. Natl. Acad. Sci. U. S. A. 98, 12215-12220.

(4) Challis, G. L. (2008) Genome mining for novel natural product discovery. J. Med. Chem. 51, 2618-2628.

(5) Scherlach, K., and Hertweck, C. (2009) Triggering cryptic natural product biosynthesis in microorganisms. Org. Biomol. Chem. 7, 175360.

(6) Choquer, M., Fournier, E., Kunz, C., Levis, C., Pradier, J. M., Simon, A., and Viaud, M. (2007) Botrytis cinerea virulence factors: New insights into a necrotrophic and polyphageous pathogen. FEMS Microbiol. Lett. 277, 1-10.

(7) Williamson, B., Tudzynski, B., Tudzynski, P., and van Kan, J. A. L. (2007) Botrytis cinerea: the cause of grey mould disease. Mol. Plant Pathol. 8, 561-80.

(8) Colmenares, A. J., Aleu, J., Durán-Patrón, R, Collado, I. G., and Hernández-Galán, R. (2002) The putative role of botrydial and related metabolites in the infection mechanism of Botrytis cinerea. J. Chem. Ecol. 28, 997-1005.

(9) Tani, H., Koshino, H., Sakuno, E., and Nakajima, H. (2005) Botcinins A, B, C, and D, metabolites produced by Botrytis cinerea, and their antifungal activity against Magnaporthe grisea, a pathogen of rice blast disease. J. Nat. Prod. 68, 1768-72.

(10) Tani, H., Koshino, H., Sakuno, E., Cutler, H. G., and Nakajima, H. (2006) Botcinins $\mathrm{E}$ and $\mathrm{F}$ and Botcinolide from Botrytis cinerea and structural revision of botcinolides. J. Nat. Prod. 69, 722-5.

(11) Deighton, N., Muckenschnabel, I., Colmenares, A. J., Collado, I. G., and Williamson, B. (2001) Botrydial is produced in plant tissues infected by Botrytis cinerea. Phytochemistry 57, 689-692.

(12) Cutler, H. G., Parker, S. R., Ross, S. a, Crumley, F. G., and Schreiner, P. R. (1996) Homobotcinolide: a biologically active natural homolog of botcinolide from Botrytis cinerea. Biosci., Biotechnol., Biochem. 60, 656-658.

(13) Sakuno, E., Tani, H., and Nakajima, H. (2007) 2-epi-botcinin A and 3-O-acetylbotcineric acid from Botrytis cinerea. Biosci., Biotechnol., Biochem. 71, 2592-2595.

(14) Marumo, S., Katayama, M., Komori, E., Ozaki, Y., Natsume, M., and Kondo, S. (1982) Microbial production of abscisic acid by Botrytis cinerea. Agric. Agric. Biol. Chem. 46, 1967-1968.

(15) Amselem, J., Cuomo, C. A., van Kan, J. A. L., Viaud, M., Benito, E. P., Couloux, A., Coutinho, P. M., de Vries, R. P., Dyer, P. S., Fillinger, S., Fournier, E., Gout, L., Hahn, M., Kohn, L., Lapalu, N., Plummer, K. M., Pradier, J. M., Quévillon, E., Sharon, A., Simon, A., ten Have, A., Tudzynski, B., Tudzynski, P., Wincker, P., Andrew, M., Anthouard, V., Beever, R. E., Beffa, R., Benoit, I., Bouzid, O., Brault, B., Chen, Z., Choquer, M., Collémare, J., Cotton, P., Danchin, E. G., Da Silva, C., Gautier, A., Giraud, C., Giraud, T., Gonzalez, C., Grossetete, S., Güldener, U., Henrissat, B., Howlett, B. J., Kodira, C., Kretschmer, M., Lappartient, A., Leroch, M., Levis, C., Mauceli, E., Neuvéglise, C., Oeser, B., Pearson, M., Poulain, J., Poussereau, N., Quesneville, H., Rascle, C., Schumacher, J., Ségurens, B., Sexton, A., Silva, E., Sirven, C., Soanes, D. M., Talbot, N. J., Templeton, M., Yandava, C., Yarden, O., Zeng, Q. Rollins, J. a., Lebrun, M. H., and Dickman, M. (2011) Genomic analysis of the necrotrophic fungal pathogens Sclerotinia sclerotiorum and Botrytis cinerea. PLoS Genet. 7, e1002230.

(16) Laliberté, J., and Labbé, S. (2006) Mechanisms of copper loading on the Schizosaccharomyces pombe copper amine oxidase 1 expressed in Saccharomyces cerevisiae. Microbiology 152, 2819-2830.

(17) Saitoh, Y., Izumitsu, K., Morita, A., and Tanaka, Ch. (2010) A copper-transporting ATPase BcCCC2 is necessary for pathogenicity of Botrytis cinerea. Mol. Genet. Genomics 284, 33-43.

(18) Bode, H. B., Walker, M., and Zeeck, A. (2000) Secondary metabolites by chemical screening, 41 structure and biosynthesis of mutolide, a novel macrolide from a UV mutant of the fungus F-24'707. Eur. J. Org. Chem. 2000, 1451-1456.

(19) Bode, H. B., Bethe, B., Höfs, R., and Zeeck, A. (2002) Big effects from small changes: Possible ways to explore nature's chemical diversity. ChemBioChem 3, 619-627.

(20) Grond, S., Papastavrou, I., and Zeeck, A. (2002) Novel $\alpha$-LRhamnopyranosides from a Single Strain of Streptomyces by Supplement-Induced Biosynthetic Steps. Eur. J. Org. Chem. 2002, 3237-3242.

(21) Bowers, W. S., Nishino, C., Montgomery, M. E., Nault, L. R, and Nielson, M. W. (1977) Sesquiterpene progenitor, germacrene A: an alarm pheromone in aphids. Science 196, 680-681.

(22) Stoessl, A., Stothers, J. B., and Ward, E. W. B. (1976) Sesquiterpenoid stress compounds of the Solanaceae. Phytochemistry $15,855-872$.

(23) Proctor, R. H., and Hohn, T. M. (1993) Aristolochene synthase. Isolation, characterization, and bacterial expression of a sesquiterpenoid biosynthetic gene (Ari1) from Penicillium roqueforti. J. Biol. Chem. $268,4543-4548$

(24) Dalmais, B., Schumacher, J., Moraga, J., LE Pêcheur, P., Tudzynski, B., Collado, I. G., and Viaud, M. (2011) The Botrytis cinerea phytotoxin botcinic acid requires two polyketide synthases for production and has a redundant role in virulence with botrydial. Mol. Plant Pathol. 12, 564-79.

(25) Maldonado-Bonilla, L. D., Betancourt-Jiménez, M., and LozoyaGloria, E. (2008) Local and systemic gene expression of sesquiterpene phytoalexin biosynthetic enzymes in plant leaves. Eur. J. Plant Pathol. 121, 439-449.

(26) Zhao, Y., Schenk, D. J., Takahashi, S., Chappell, J., and Coates, R. M. (2004) Eremophilane sesquiterpenes from capsidiol. J. Org. Chem. 69, 7428-35.

(27) Cane, D. E., Rawlings, B. J., and Yang, C. (1987) Isolation of $(-)-\gamma$-cadinene and aristolochene from Aspergillus terreus. J. Antibiot. 40 (9), 1331-1334.

(28) Freire, F., Seco, J. M., Quiñoá, E., and Riguera, R. (2005) Determining the absolute stereochemistry of secondary/secondary diols by $1 \mathrm{H}$ NMR: Basis and applications. J. Org. Chem. 70, 37783790.

(29) González-Rodríguez, V. E., Liñeiro, E., Colby, T., Harzen, A., Garrido, C., Cantoral, J. M., Schmidt, J., and Fernández-Acero, F. J. (2015) Proteomic profiling of Botrytis cinerea conidial germination. Arch. Microbiol. 197, 117-133.

(30) Stürzenbaum, S. R., and Kille, P. (2001) Control genes in quantitative molecular biological techniques: The variability of invariance. Comp. Biochem. Physiol., Part B: Biochem. Mol. Biol. 130, 281-289.

(31) Gil-Salas, F. M., Morris, J., Colyer, A., Budge, G., Boonham, N., Cuadrado, I. M., and Janssen, D. (2007) Development of real-time RT-PCR assays for the detection of Cucumber vein yellowing virus (CVYV) and Cucurbit yellow stunting disorder virus (CYSDV) in the whitefly vector Bemisia tabaci. J. Virol. Methods 146, 45-51.

(32) Pinedo, C., Wang, C. M., Pradier, J. M., Dalmais, B., Choquer, M., Le Pêcheur, P., Morgant, G., Collado, I. G., Cane, D. E., and Viaud, M. (2008) Sesquiterpene synthase from the botrydial biosynthetic gene cluster of the phytopathogen Botrytis cinerea. ACS Chem. Biol. 3, 791-801.

(33) Ugalde, U. (2006) Autoregulatory signals in mycelial fungi. Growth, Differentiation and Sexuality. (Kües, U. and Fischer, R., Ed.) 203-213, Springer.

(34) Leeder, A. C., Palma-Guerrero, J., and Glass, N. L. (2011) The social network: deciphering fungal language. Nat. Rev. Microbiol. 9, $440-451$.

(35) Katayama, M., Yanagi, M., and Marumo, S. (1989) Isolation of sporogen-PF 1, a blue light-induced sporogenic substance, from Penicillium funiculosum. Agric. Biol. Chem. 53, 3379-3380.

(36) Adams, T. H., Wieser, J. K., and Yu, J. H. (1998) Asexual sporulation in Aspergillus nidulans. Microbiol. Mol. Biol. Rev. 62, 35-54.

(37) Rodriguez-Urra, A. B., Jiménez, C., Nieto, M. I., Rodríguez, J., Hayashi, H., and Ugalde, U. (2012) Signaling the induction of 
sporulation involves the interaction of two secondary metabolites in Aspergillus nidulans. ACS Chem. Biol. 7 (3), 599-606.

(38) Backhouse, D., and Willetts, H. J. (1987) Development and structure of infection cushions of Botrytis cinerea. Trans. Br. Mycol. Soc. 89, 89-95.

(39) Garcia-Arenal, F., and Sagasta, E. M. (1980) Scanning Electron Microscopy of Botrytis cinerea Penetration of Bean (Phaseolus vulgaris) Hypocotyls. J. Phytopathol. 99, 37-43.

(40) Buhr, T. L., and Dickman, M. B. (1997) Gene expression analysis during conidial germ tube and appressorium development in Colletotrichum trifolii. Appl. Environ. Microbiol. 63, 2378-2383.

(41) Lee, Y.-H., and Dean, R. A. (1994) Hydrophobicity of contact surface induces appressorium formation in Magnaporthe grisea. FEMS Microbiol. Lett. 115, 71-75.

(42) Garrido, C., Carbú, M., Fernández-Acero, F. J., Vallejo, I., and Cantoral, J. M. (2009) Phylogenetic relationships and genome organization of Colletotrichum acutatum causing anthracnose in strawberry. Eur. J. Plant Pathol. 125 (3), 397-411.

(43) Froehlich, A. C., Noh, B., Vierstra, R. D., Loros, J., and Dunlap, J. C. (2005) Genetic and molecular analysis of phytochromes from the filamentous fungus Neurospora crassa. Eukaryotic Cell 4, 2140-2152. 